\title{
Experimental Analysis on Shrinkage and Swelling in Ordinary Concrete
}

\author{
Barbara Kucharczyková, Petr Daněk, Dalibor Kocáb, and Petr Misák \\ Faculty of Civil Engineering, Brno University of Technology, Veveři 331/95, 60200 Brno, Czech Republic \\ Correspondence should be addressed to Barbara Kucharczyková; barbara.kucharczykova@vutbr.cz
}

Received 2 March 2017; Accepted 23 April 2017; Published 22 May 2017

Academic Editor: Katsuyuki Kida

Copyright (C) 2017 Barbara Kucharczyková et al. This is an open access article distributed under the Creative Commons Attribution License, which permits unrestricted use, distribution, and reproduction in any medium, provided the original work is properly cited.

\begin{abstract}
The paper deals with the experimental determination of shrinkage development during concrete ageing. Three concrete mixtures were made. They differed in the amount of cement in the fresh mixture, 300,350 , and $400 \mathrm{~kg} / \mathrm{m}^{3}$. In order to determine the influence of plasticiser on the progress of volume changes, another three concrete mixtures were prepared with plasticiser in the amount of $0.25 \%$ by cement mass. Measurements were performed with the goal of observing the influence of cement and plasticiser content on the overall development of volume changes in the concrete. Changes in length and mass losses of the concrete during ageing were measured simultaneously. The continuous measurement of concrete mass losses caused by drying of the specimen's surface proved useful during the interpretation of results obtained from the concrete shrinkage measurement. During the first 24 hours of ageing, all the concrete mixtures exhibited swelling. Its magnitude and progress were influenced by cement, water, and plasticiser content. However, a loss of mass caused by water evaporation from the surface of the specimens was also recorded in this stage. The measured progress of shrinkage corresponded well to the progress of mass loss.
\end{abstract}

\section{Introduction}

Concrete shrinkage can be defined as a volume change that takes place during two consecutive stages of concrete ageing, the early stage of setting and the long-term stage of hardening [1]. These changes are in both cases connected with moisture leaving the fresh or hardened concrete. Generally speaking, three main categories of shrinkage can be recognised - plastic shrinkage, chemical shrinkage (which includes autogenous shrinkage), and shrinkage due to drying. Some sources mention concrete swelling [2-7]. From the long-term point of view also the carbonation shrinkage must be taken into account. The determination of the real progress of volume changes of concrete has received increased attention from civil engineers and concrete producers in recent years. This is connected mainly with the development of new concretes as far as composition and production technology is concerned $[3,8-10]$. Scientific sources describe a number of approaches for determining the value of concrete shrinkage $[5,11,12]$. However, these are mostly methods for separately determining the individual components of concrete shrinkage in the early age, such as methods for determining plastic or autogenous shrinkage, described, for example, in $[2,3,6,7$, $12,13]$, and methods for determining concrete shrinkage due to drying, which are defined mostly in the national standards of various countries. Thus, contemporary experimental measurements are not sufficient for capturing the total change in concrete volume caused by chemical reactions, plastic settlement, and drying. These influences have either larger or smaller significance in every stage of concrete ageing. While the total sum of these influences can be very significant in the early stage of setting and hardening, the most significant influence from a long-term perspective appears to be concrete drying [4].

Contemporary approaches to concrete shrinkage measurement are based mainly on the determination of relative length change. In most cases, measurement begins after specimens have been removed from their moulds, which is typically no sooner than the age of 24 hours. In important or complicated concrete structures, shrinkage is measured directly on a concrete element using a special type of wire strain gauge designed to be embedded in the concrete. 
Such gauges are typically tied to the reinforcement cage of the measured element by means of rebar extensions [1418]. However, this measurement is very expensive and it is usually not possible to draw generalisations from the results. In practical terms, it is more advantageous to determine the progress of the volume changes in concrete by testing specimens in a laboratory.

The significance of each type of shrinkage is strongly dependent on the composition of the composite, the curing method, and the size of the test specimen [19]. Experience gained from measurements performed in recent years indicates the necessity of assessing the magnitude of shrinkage in two basic stages, in the early stage of setting and hardening (roughly up to 48 hours after mixing cement with water) and at "later ages" which can be counted from $48 \mathrm{~h}$ of concrete ageing. After cement has been mixed with water, they react together and chemical shrinkage occurs. Along with the chemical shrinkage, autogenous shrinkage also appears. Autogenous shrinkage occurs for as long as there is water present in the pore structure. For this reason, this phenomenon is often called self-desiccation shrinkage $[1$, 4]. Very soon after fresh concrete has been made, plastic shrinkage also takes place. This is in a very early stage when the concrete is still fresh and a solid structure which would "hold the body in place" has not yet formed. The magnitude of plastic shrinkage depends on the evaporation of water from fresh concrete or its absorption into a dry concrete body or soil underneath $[4,20]$. Its magnitude is also influenced by fresh mixture bleeding.

A no less important, yet often neglected, type of volume change is deformation caused by temperature change. Such volume changes can be observed at the early stage of setting as well as throughout hardening and long-term ageing. In their paper from 1997, Tazawa and Miyazawa discuss the influence of temperature on autogenous shrinkage; as temperature rises, the magnitude of autogenous shrinkage at an early age increases, while at later ages this influence appears negligible. In her extensive scientific work from 2001 [2], Holt discusses the connection between temperature increase in concrete and its thermal expansion during the early stage of setting and hardening. Amin et al. have also dealt with the influence of temperature on shrinkage of concrete during this period, which they discuss in detail in a paper published in 2010 [21].

In recent years there has been greatly increased interest in determining volume changes in concrete at an early age. Also, the term "concrete swelling" can be encountered more and more frequently in connection with the phenomenon observable in the first 24 hours after the mixing of cement with water. The authors of this paper dealt with this phenomenon more extensively in 2006 during the experimental verification of a method of measuring volume changes in concrete cast in shrinkage drains produced by Schleibinger [12]. Very interesting results have been obtained during measurements performed on concretes with different porous aggregate contents, or during the observation of the influence of the water saturation of porous aggregate on volume changes in lightweight concrete. There are several factors which can be at the origin of this phenomenon. In most cases concrete swelling is connected with excess free water in the
TABLE 1: Identification of test concretes.

\begin{tabular}{lcc}
\hline $\begin{array}{l}\text { Assumed cement } \\
\text { dosage }[\mathrm{kg}]\end{array}$ & No plasticiser & $\begin{array}{c}\text { Plasticiser } \\
0.25 \% \text { of cement mass }\end{array}$ \\
\hline 300 & $\mathbf{0} / \mathbf{1}$ & $\mathbf{1} / \mathbf{1}$ \\
350 & $\mathbf{0} / \mathbf{2}$ & $\mathbf{1} / \mathbf{2}$ \\
400 & $\mathbf{0 / 3}$ & $\mathbf{1 / 3}$ \\
\hline
\end{tabular}

concrete mixture which causes the concrete to bleed. This excess water is drawn back into the hardened cement paste by weak capillary suction after plastic settling has finished. This reabsorption is the cause of swelling [2, 22, 23]. Swelling can also be strengthened by the formation of some expansive hydration products, absorption of water into the $\mathrm{C}-\mathrm{S}-\mathrm{H}$ gel $[4,7]$, or the generation of hydration heat [2]. Swelling also occurs in concretes which are entirely submerged in water [4].

It appears that in most traditional cement composites the most substantial part of the total amount of shrinkage is actually deformation caused by drying. This deformation occurs throughout setting and hardening and can be reduced via suitable composition design and especially by choosing a suitable curing method for the final concrete element. Shrinkage due to drying occurs in all types of cement composites placed in an environment with relative humidity $<95 \%$ [20].

\section{Experimental Part}

2.1. Tested Material. The experiments draw on results published within the project GAČR 13-18870S [24-27]. The purpose of the measurements was to determine volume changes in ordinary concrete and especially to record the progress of early and later-age shrinkage. The basic formula of the concrete consisted of dense aggregate with a maximum particle size of $16 \mathrm{~mm}$, CEM I $42.5 \mathrm{R}$ Portland cement and water. Three concrete mixtures were made which differed in cement content. They differed in the amount of cement in the fresh mixture, 300,350 , and $400 \mathrm{~kg} / \mathrm{m}^{3}$. In order to determine the influence of plasticiser on the progress of volume changes, another three concrete mixtures were prepared with plasticiser in the amount of $0.25 \%$ by cement mass (polycarboxylate ether based technology). The amount of cement in the fresh mixture was the same like in the reference mixtures without plasticiser. In total six different mixtures, three with plasticiser and three without, were prepared for the experiment (see Table 1). Water content was adjusted to achieve approximately the same workability in all the concretes. Measurements were then performed with the aim of examining the influence of cement and plasticiser content on the overall progress of volume changes in the concrete. A large number of specimens were made from each type of concrete, each being approx. $0.4 \mathrm{~m}^{3}$ in volume. In order to ensure the homogeneity of the amount of concrete necessary for making all the specimens, all concrete mixtures were produced in a concrete mixing tower. For more detailed information on the compositions of the concrete mixtures, see Table 2. Also, Table 3 lists the mixtures' basic properties in the fresh state. These properties are directly connected with 
TABLE 2: Composition of fresh concretes.

\begin{tabular}{|c|c|c|c|c|c|c|c|}
\hline \multirow{2}{*}{ Components per $1 \mathrm{~m}^{3}$ of fresh concrete } & \multirow{2}{*}{ Units } & \multicolumn{6}{|c|}{ Concrete ID } \\
\hline & & $0 / 1$ & $0 / 2$ & $0 / 3$ & $1 / 1$ & $1 / 2$ & $1 / 3$ \\
\hline CEM I 42.5 R (Mokrá) & {$[\mathrm{kg}]$} & 300 & 350 & 400 & 300 & 350 & $\overline{400}$ \\
\hline Sand (Bratčice) 0-4 & {$[\mathrm{kg}]$} & 925 & 875 & 825 & 925 & 875 & 825 \\
\hline Aggregate (Olbramovice) $4-8$ & {$[\mathrm{~kg}]$} & 185 & 185 & 185 & 185 & 185 & 185 \\
\hline Aggregate (Olbramovice) 8-16 & {$[\mathrm{kg}]$} & 695 & 695 & 695 & 695 & 695 & 695 \\
\hline \multicolumn{8}{|l|}{ Water } \\
\hline Mixing & {$[\mathrm{kg}]$} & 190 & 190 & 190 & 165 & 165 & 165 \\
\hline In aggregate & {$[\mathrm{kg}]$} & 14 & 14 & 14 & 14 & 14 & 14 \\
\hline Total & {$[\mathrm{kg}]$} & 204 & 204 & 204 & 179 & 179 & 179 \\
\hline Sika ViscoCrete 4035 & {$[\mathrm{~kg}]$} & 0 & 0 & 0 & 0.75 & 0.88 & 1.00 \\
\hline $\mathrm{w} / \mathrm{c}$ ratio $\left(\mathrm{w}_{\text {mixing }} /\right.$ cement $)$ & {$[-]$} & 0.63 & 0.54 & 0.48 & 0.55 & 0.47 & 0.41 \\
\hline
\end{tabular}

TABLE 3: Basic properties of fresh concretes.

\begin{tabular}{|c|c|c|c|c|c|c|}
\hline Concrete ID & $0 / 1$ & $0 / 2$ & $0 / 3$ & $1 / 1$ & $1 / 2$ & $1 / 3$ \\
\hline Bulk density of fresh concrete $\left[\mathrm{kg} / \mathrm{m}^{3}\right]$ & 2,320 & 2,320 & 2,290 & 2,280 & 2,300 & 2,300 \\
\hline Flow table $[\mathrm{mm}]$ & 410 & 390 & 420 & 360 & 350 & 370 \\
\hline Air content [\%] & 2.7 & 2.5 & 2.5 & 2.6 & 2.8 & 3.2 \\
\hline
\end{tabular}

concrete behaviour especially during the early stage of its setting. The properties of the fresh concrete were determined in accordance with ČSN EN 12350 [28].

Two parameters were observed during the measurement, namely, relative length deformation (shrinkage/swelling) and mass loss (evaporation of water from the surface of the concrete). Three test specimens, shrinkage drains filled with concrete, were manufactured from each mixture.

2.2. Test Equipment and Procedure. The measurement of shrinkage was performed using a testing device made by the company Schleibinger Geräte Teubert u. Greim GmbH [12]. Shrinkage drains of $1000 \mathrm{~mm}$ in length and $60 \times 100 \mathrm{~mm}$ in cross-section were used for recording the length changes measured along the central axis of the specimens using an inductivity sensor leaning against the movable head of the drain. These drains are primarily designed for shrinkage measurement in the early stage of cement composite setting and hardening. Special markers were embedded into the upper surface of the concrete placed in the shrinkage drains in order to facilitate subsequent long-term measurement of relative deformation. In this way, two gauging bases were created for further measurement (see Figure 1). This arrangement enables the continuous capture of the total relative length changes of the concrete since the moment the concrete is placed into the drain until its long-term ageing after the specimen has been removed from the shrinkage drain. Details about the marker types, drawing and their arrangement can be found in [29]. Figure 1 shows the shrinkage drains filled with concrete and ready for measurement.

The shrinkage drains were filled with concrete and placed onto a special weighing table which allowed continuous recording of mass losses caused by free drying of the specimen surfaces (see Figure 2). In this way, changes in the length and mass losses of the concrete in the shrinkage drains

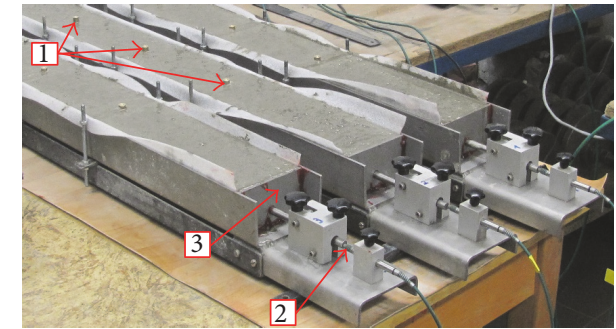

FIGURE 1: Shrinkage drains ready for measurement (1: embedded markers; 2: inductivity sensor; 3: movable head).

were measured simultaneously (see Figure 2). The design of the weighing table as well as the details of the measurement procedure are protected by industrial property rights held by Brno University of Technology registered in the national patent database under application number 2013-961 [30]. For details about measurement techniques see [31].

Due to the consistency of the fresh concrete, measurement was started approximately one hour after the concrete was poured into the drains. Shrinkage was measured in the drains placed on the weighing table in a laboratory at a temperature of $21 \pm 2^{\circ} \mathrm{C}$ and relative humidity of $83 \pm 3 \%$ until the concrete was 3 days old. The top surface of the concrete was not protected from drying. The specimens were then extracted from the drains and stored in a laboratory at a stable temperature of $21 \pm 2^{\circ} \mathrm{C}$ and relative humidity of $55 \pm 3 \%$. Further measurements were performed using a Hollan strain gauge (see Figure 3) which was fixed onto the surface of the specimens. The positioning of the gauging points was predefined by the markers embedded at spacing of $200 \mathrm{~mm}$. The specimens were then left to dry freely for the entire time of measurement and were weighed at regular intervals. 
TABLE 4: Basic characteristics of hardened concretes.

\begin{tabular}{|c|c|c|c|c|c|c|}
\hline & $0 / 1$ & $0 / 2$ & $0 / 3$ & $1 / 1$ & $1 / 2$ & $1 / 3$ \\
\hline Bulk density $\left[\mathrm{kg} / \mathrm{m}^{3}\right]$ & $\begin{array}{c}2310 \\
(11.0)\end{array}$ & $\begin{array}{c}2320 \\
(8.62)\end{array}$ & $\begin{array}{c}2330 \\
(18.5)\end{array}$ & $\begin{array}{c}2320 \\
(8.08)\end{array}$ & $\begin{array}{c}2330 \\
(4.04)\end{array}$ & $\begin{array}{l}2360 \\
(1.73)\end{array}$ \\
\hline Compressive strength $\left[\mathrm{N} / \mathrm{mm}^{2}\right]$ & $\begin{array}{c}33.3 \\
(0.19)\end{array}$ & $\begin{array}{c}44.5 \\
(0.49)\end{array}$ & $\begin{array}{c}55.8 \\
(2.23)\end{array}$ & $\begin{array}{c}42.8 \\
(0.84)\end{array}$ & $\begin{array}{c}50.8 \\
(0.22)\end{array}$ & $\begin{array}{c}56.4 \\
(2.21)\end{array}$ \\
\hline Dynamic modulus of elasticity $E_{\text {crL }}\left[\mathrm{N} / \mathrm{mm}^{2}\right]$ & $\begin{array}{c}29000 \\
(503)\end{array}$ & $\begin{array}{c}34600 \\
(661)\end{array}$ & $\begin{array}{c}35000 \\
(281)\end{array}$ & $\begin{array}{c}30600 \\
(563)\end{array}$ & $\begin{array}{l}31200 \\
(670)\end{array}$ & $\begin{array}{c}32900 \\
(671)\end{array}$ \\
\hline
\end{tabular}

Note. All materials' characteristics are represented by mean values and (standard deviation) both introduced in the same units. Values of dynamic modulus of elasticity $E_{\text {crL }}$ were determined using the resonance method according to [32].

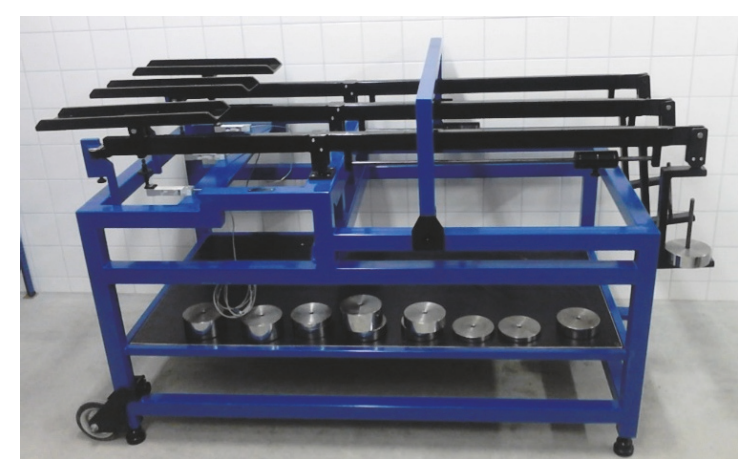

(a)

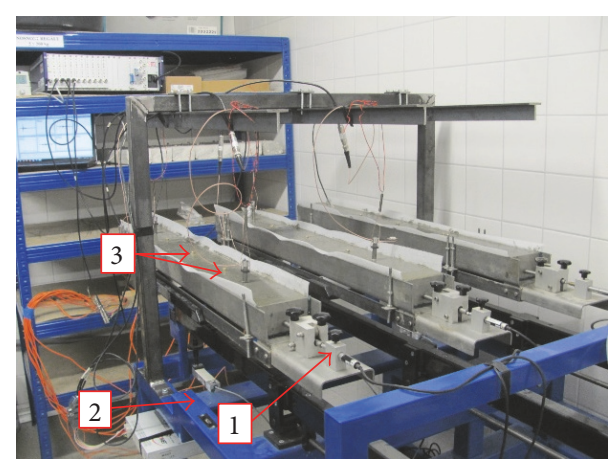

(b)

Figure 2: Weighing table for continuous measurement of mass loss (a); shrinkage drains placed on the weighing table (1: shrinkage drain with the inductivity sensor; 2 : weighing table; 3 : embedded markers).

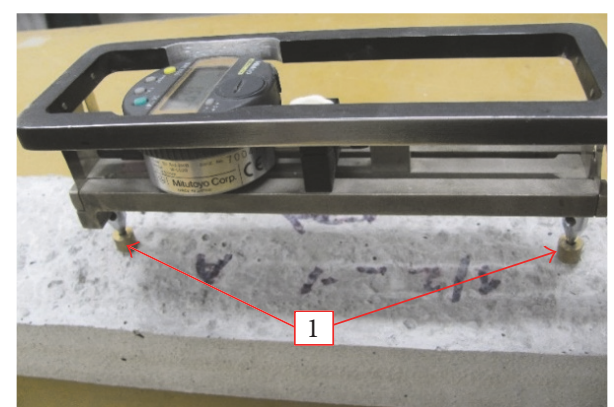

FIGURE 3: A Hollan strain gauge (1: embedded markers).

\section{Results and Discussion}

The measurement results are presented here mainly in visual form. To introduce the tested concretes their basic materials' characteristics in hardened state are summarized in Table 4.

For clarity, measurement at an early age, that is, concrete in shrinkage drains, is shown separately from the progress of total shrinkage, that is, measurement in the shrinkage drains as well as measurement after the specimens were removed. Generally speaking, the observed influences, that is, cement and plasticiser content, are not very significant in terms of the values of total deformation. Concerning cement dosage (Figure 4(a), on the upper part), the greatest total shrinkage determined at the age of 300 days was recorded in concrete $0 / 1$. However, the value of shrinkage in comparison with other concretes $(0 / 2$ and $0 / 3)$ is different by no more than $150 \mu \mathrm{m} / \mathrm{m}$. The progress and values of mass losses recorded over the whole time of measurement were the same for all the concretes being examined. Rather interesting results were observed in the measurements recorded in the early stage of concrete setting and hardening. Figure 4(b) shows the progress of the shrinkage of concretes with different cement content. The results indicate a different behaviour of each concrete in the first 24 hours of ageing. The diagram shows that shortly after commencing the measurement, all the concretes swell despite water evaporation (as seen from the mass losses, Figure 4(b), bottom part). It can also be observed that the swelling time moves along with an increase in cement content. While the stage of swelling in the case of concrete $0 / 1$ ( $300 \mathrm{~kg}$ of cement per $1 \mathrm{~m}^{3}$ of fresh concrete) ends approx. 18 hours after the beginning of measurement, in the case of concrete $0 / 2\left(350 \mathrm{~kg} / \mathrm{m}^{3}\right.$ as above $)$ the duration of swelling is 24 hours and for concrete $0 / 3\left(400 \mathrm{~kg} / \mathrm{m}^{3}\right.$ as above) it is 30 hours. The magnitude of swelling is dependent on the amount of cement and water contained in the concrete. Generally speaking, the higher the cement dosage was, the greater the value of volume increment recorded was. The above-described progress of concrete volume changes can be explained in the following way. Firstly, this phenomenon is strongly dependent on the chemical composition, specific surface, and grading of the cement used. Secondly, the progress of swelling is also connected with moisture distribution in the pore structure of the concrete. In support of the conclusions drawn by Holt [2], this phenomenon is 

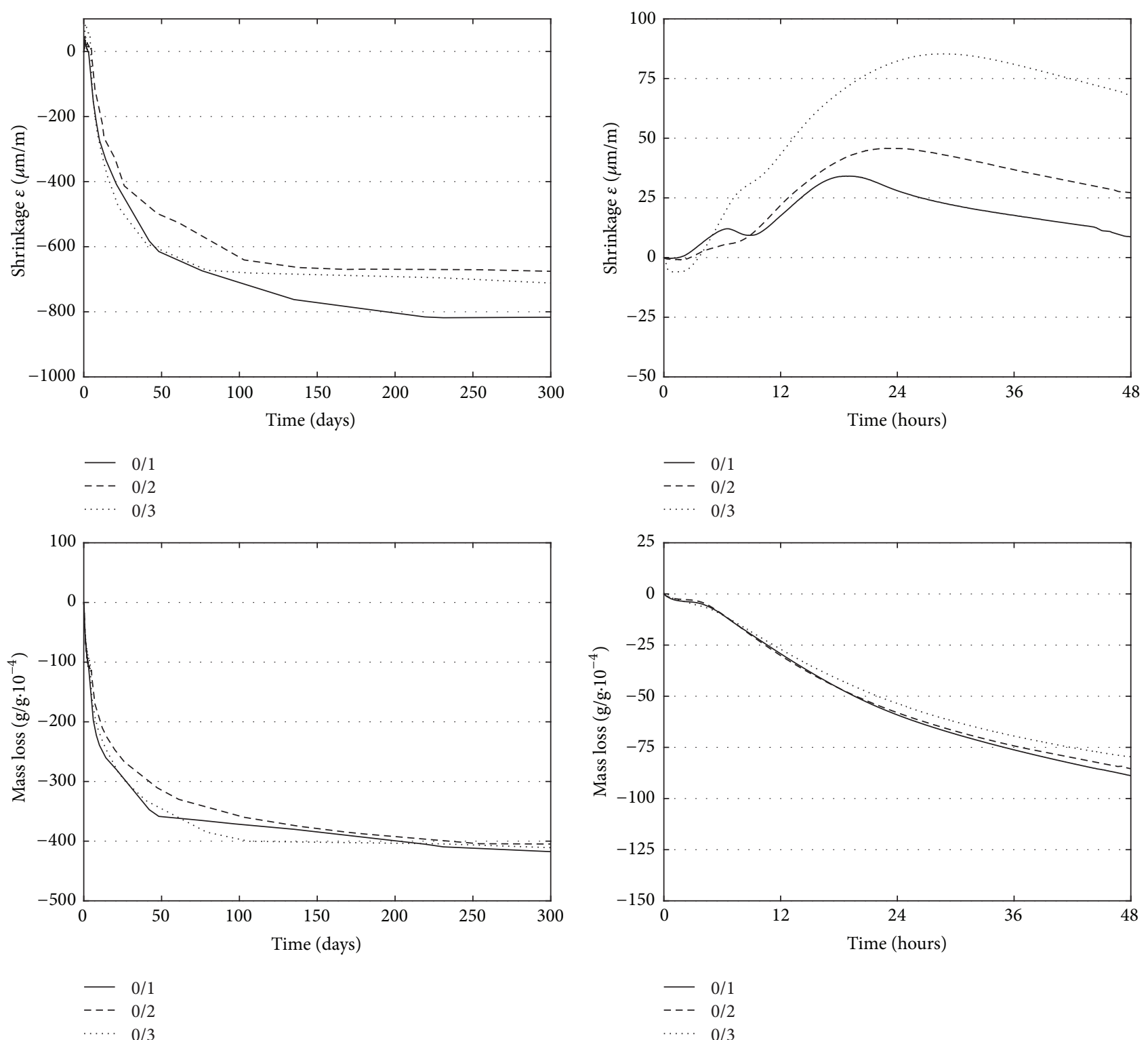

(a)
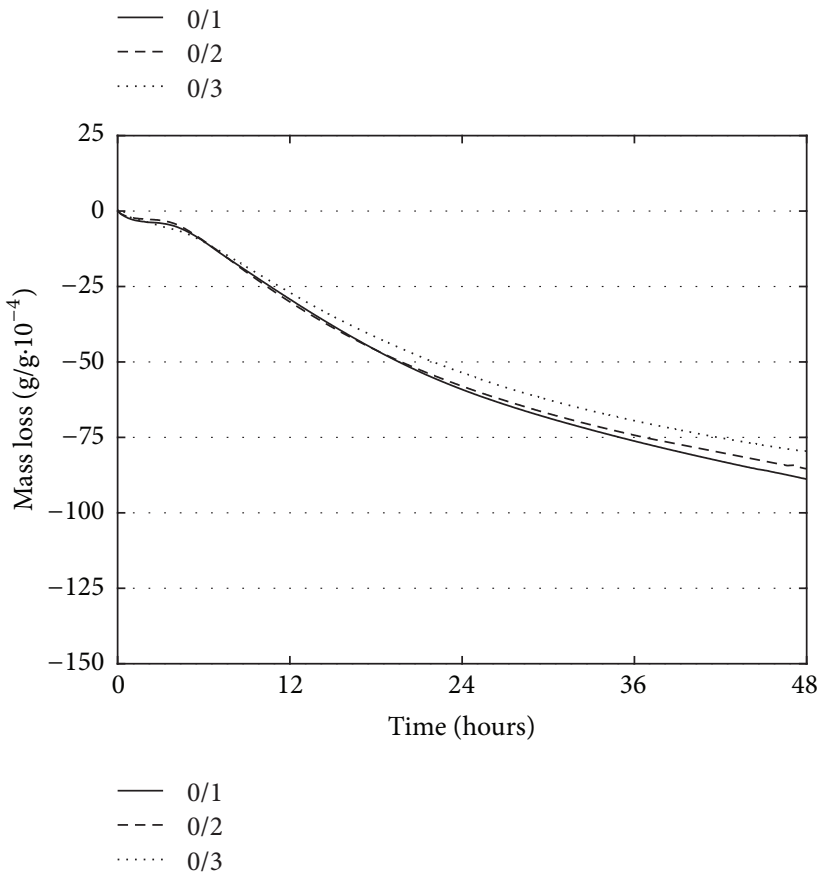

(b)

FIGURE 4: Progress of shrinkage/swelling and mass loss for concrete $0 / 1,0 / 2$, and 0/3 ((a): measurement over the whole time of setting and hardening; (b): early age measurement).

linked with the content of mixing water in concrete that rises to the surface of the composite (after aggregate and cement distribution in the fresh concrete dispersion system has stabilised) and causes concrete bleeding. After plastic settlement has finished, this excess water on the specimen upper surface is drawn back into the setting and later hardening cement paste, refilling the pores created during cement hydration. This water reabsorption causes the swelling of concrete. Similar explanation can be found in Report of RILEM Technical Committee [22], where this phenomenon is ascribed to the early autogenous deformation called as autogenous expansion. Thirdly, the swelling can also be supported by the formation of some hydration products that have a greater molar volume than the original reactants. And lastly, it is necessary to suggest that the heat generated during cement hydration has a substantial effect on the volume increase of the concrete as well because it causes its thermal expansion. The phenomenon of swelling is clearly visible from the measurements in the first 24 hours of ageing when the hydration heat is generated at the highest rate (approx. $200 \mathrm{~J} / \mathrm{g}$ per $24 \mathrm{~h}$ ) [31, 33]. The particular contribution of all the above-mentioned phenomena is the object of ongoing experimental measurement.

When the test specimens are removed from the drains and their surface is exposed to air, the water content of the concrete begins to decrease rapidly due to free desiccation which results in shrinkage of a much greater magnitude than swelling. 

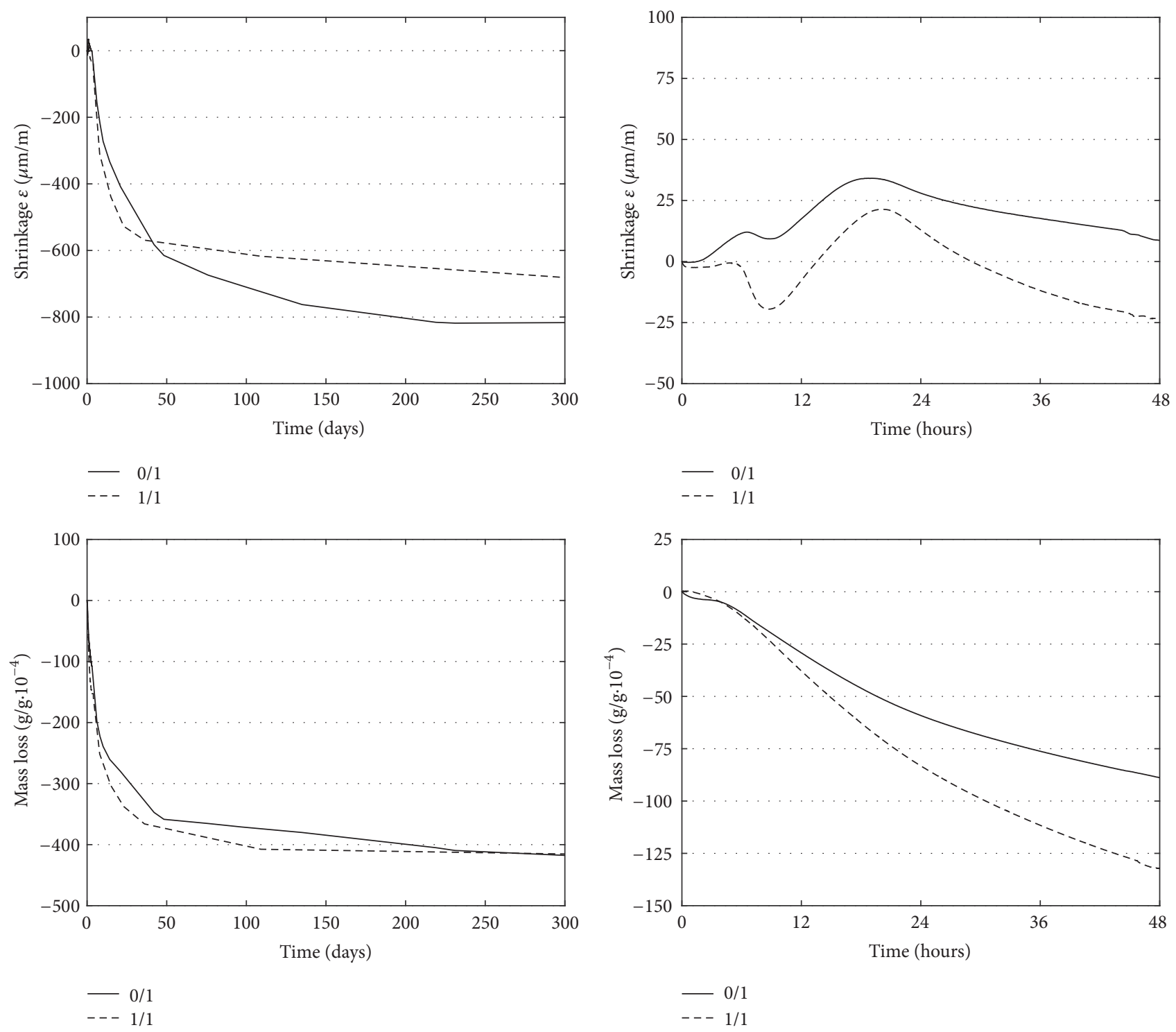

(a)

(b)

FIGURE 5: Progress of shrinkage/swelling and mass loss for concretes 0/1, and 1/1 ((a): measurement over the whole time of setting and hardening; (b): early age measurement).

Concerning the comparison of the total shrinkage of concretes with the addition of plasticiser, it can again be stated that no significant differences were recorded in the absolute values of total deformation determined for the individual concretes in the groups of concrete specimens being compared (see Figures 5-7). However, some differences were observed at the time when deformation stabilised. Concretes without plasticiser saw a relatively sharp increase in shrinkage before the age of 90 days, after which they began to stabilise. The addition of plasticiser slowed the shrinkage down already at the age of approximately 30 days. The highest difference in shrinkage values was recorded between concretes $0 / 1$ and $1 / 1$. Nevertheless, Figure 5(a) (on the upper part) shows that this difference in total shrinkage is no higher than $150 \mu \mathrm{m} / \mathrm{m}$. The values and progress of mass losses were the same for both observed concretes (see Figure 5(a) bottom part). Similar results of shrinkage progress were recorded in the case of concretes $0 / 2$ and $1 / 2$ and $0 / 3$ and $1 / 3$, respectively. These results correspond well with the measured progress of mass losses associated with cement and water dosage (see Table 2). Figures 5(b), 6(b), and 7(b) (on the bottom parts) show that, in the early stage of concrete setting and hardening, the mass of the concrete specimens with plasticiser decreases more rapidly (in comparison with the concrete without plasticiser). It can be observed that this trend is changing approximately after 7 days of concrete ageing (see Figures 6(a) and 7(a) bottom parts). Rather interesting results in terms of the progress of concrete volume changes were again obtained from the early age measurement (Figures 5(b), 6(b), and 7(b)). All the performed measurements exhibit a similar trend, concretes 

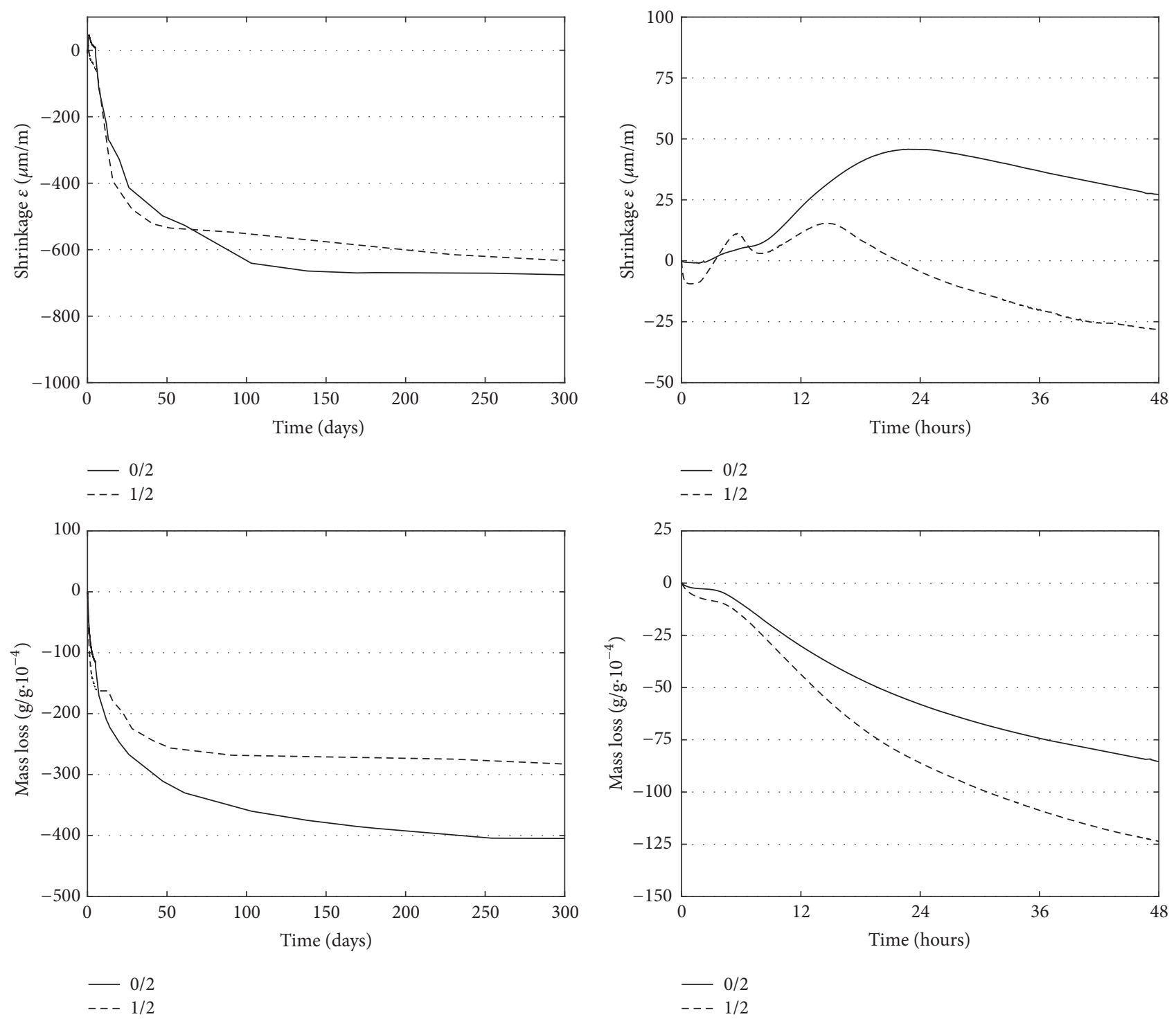

(a)

(b)

FIGURE 6: Progress of shrinkage/swelling and mass loss for concretes $0 / 2$, and 1/2 ((a): measurement over the whole time of setting and hardening; (b): early age measurement).

with plasticiser see a reduction in the value of swelling. Also, the curves of initial volume changes of the concrete with plasticiser recorded during first 48 hours of measurement differ from the curves of the concrete without plasticiser. This phenomenon is closely linked with the adjustment of water content. Once the plasticiser is added, the water content is reduced which influences the progress of the setting of the fresh concrete. This is also connected with heat flow and with the release of hydration heat in the first 24 hours of ageing. It is already known and has been proven in previous experimental measurements [33] that the addition of plasticiser has a substantial influence on cement hydration. The addition of plasticiser retards cement hydration and has a critical influence on its overall progress. The margin of hydration retardation is strongly dependent on the amount and properties of the cement and plasticiser used in the concrete mixture. Based on the measurement results it can be stated that the higher the amount of cement is, the greater the differences are in the behaviour of the concrete specimens in the groups being compared (see Figures 5(b), 6(b), and 7(b) upper parts). On the other hand, all concretes with plasticiser $(1 / 1,1 / 2$ and $1 / 3)$ exhibit very similar behaviour over the whole time of ageing, independently of the amount of cement dosage (see Figure 8). The progress of concrete volume changes at the early age corresponds well with the progress of heat flow measured for particular mixtures [33]. The smallest effect of the addition of plasticiser was found in concretes 0/1 and 1/1 (Figure 5) which, compared with other concretes, contained a low amount of cement and had a high $\mathrm{w} / \mathrm{c}$ ratio (see Tables 1 and 2). 

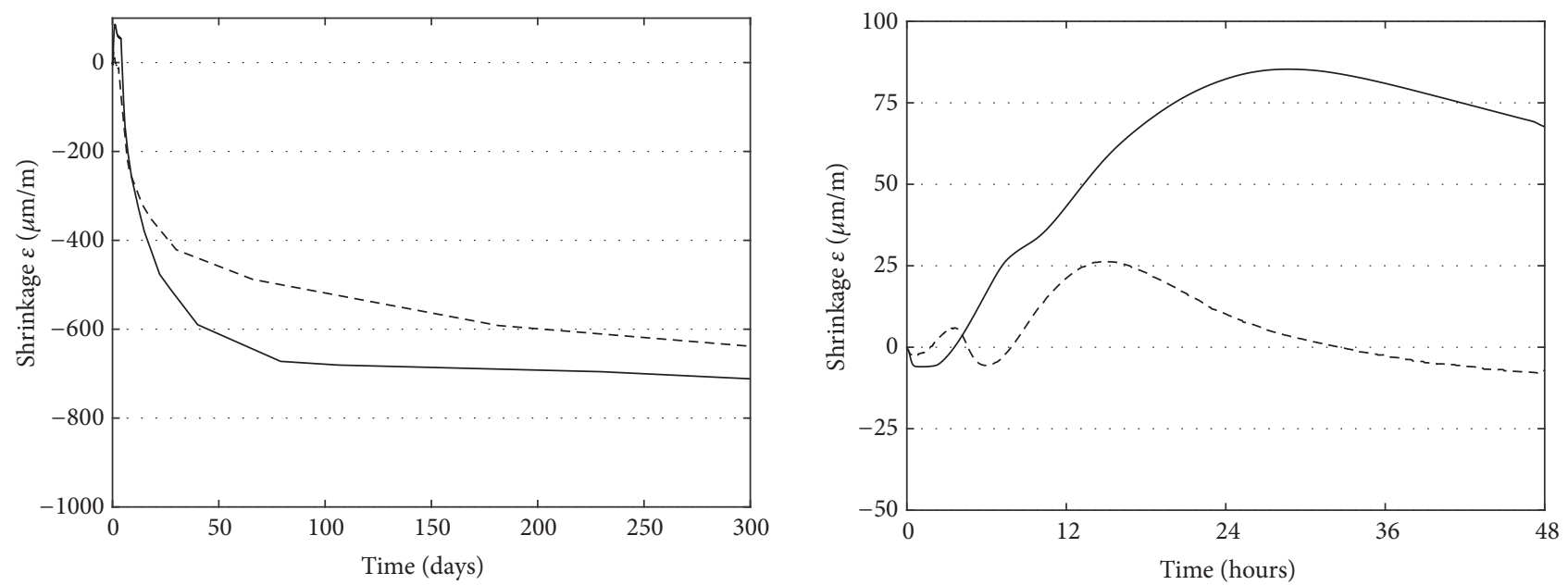

$-0 / 3$

$--1 / 3$

$-0 / 3$

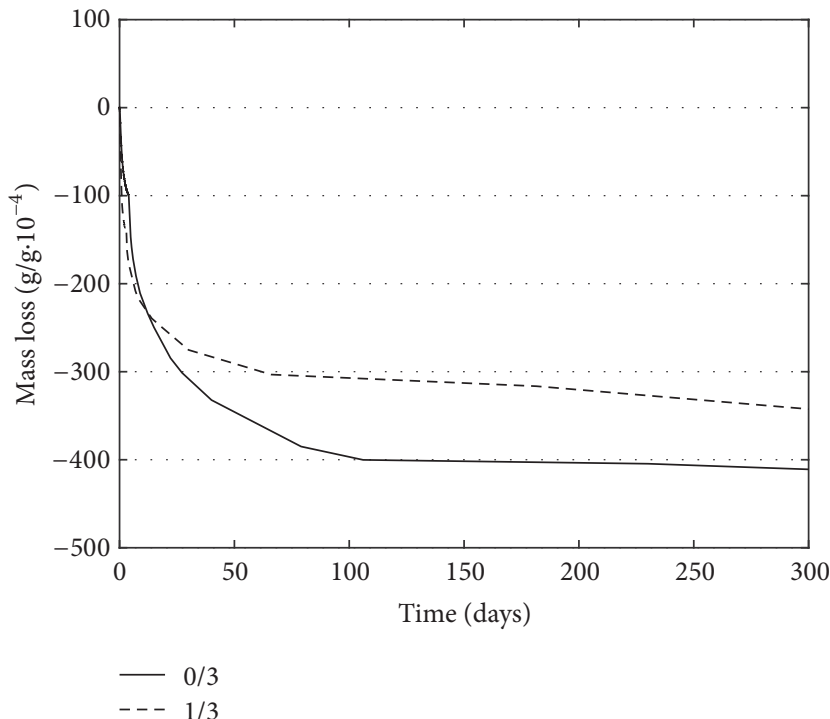

(a)

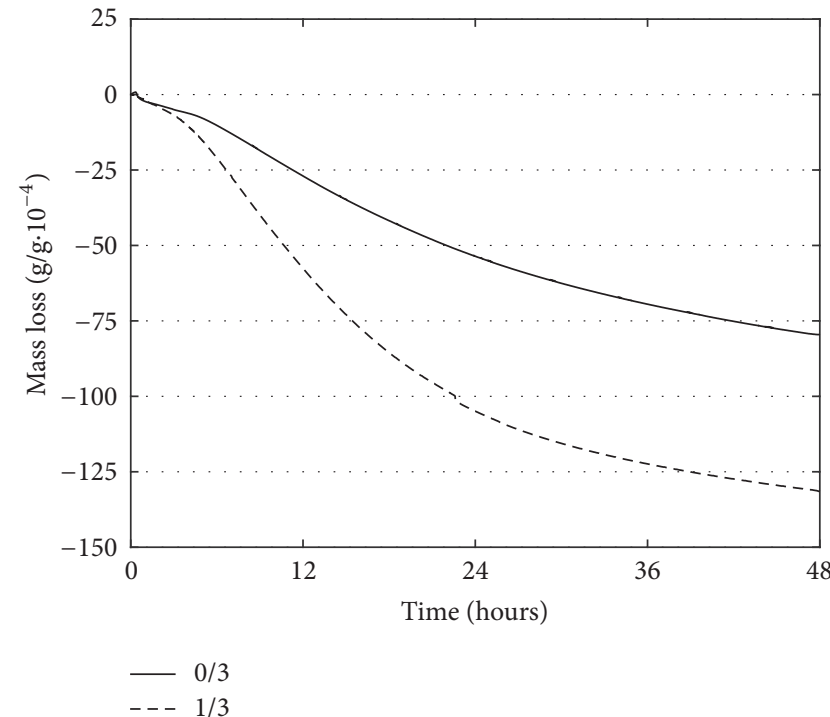

(b)

FIGURE 7: Progress of shrinkage/swelling and mass loss for concretes $0 / 3,1 / 3$, and ((a): measurement over the whole time of setting and hardening; (b): early age measurement).

Quite interesting results were observed in relationship between shrinkage and mass loss development (Figure 9). No differences are observed between mixtures $0 / 1,0 / 2$ and $0 / 3$, and $1 / 1$. However, slight differences are observed at the end of curves for mixtures $1 / 1,1 / 2$, and $1 / 3$ which shows the effect of different times when the mass of test specimens has been stabilised.

\section{Conclusion}

Recent experience with measurements indicates the necessity of assessing the magnitude of shrinkage in two basic stages, in the early stage of setting and hardening (roughly up to 48 hours after cement is mixed with water) and at the "later ages" which begin at $48 \mathrm{~h}$ and more. Performed early age measurements showed differences in the development of concretes' shrinkage which could not be detected by measurements performed on demoulded specimens (typically 24 hours after casting). Measurements conducted by different research teams showed that generalisations cannot be drawn from the absolute values of the test results but rather from the trends visible in the recorded data progress. The performed experiments confirmed this. Despite the fact that the measured early age deformations were not very significant in terms of absolute values, the results were useful for understanding the general behaviour of the concretes being examined. Continuous measurement of the mass losses caused by free drying of the test specimens' surface provided useful data for the interpretation of the results of concrete shrinkage measurement. Concerning the cement 

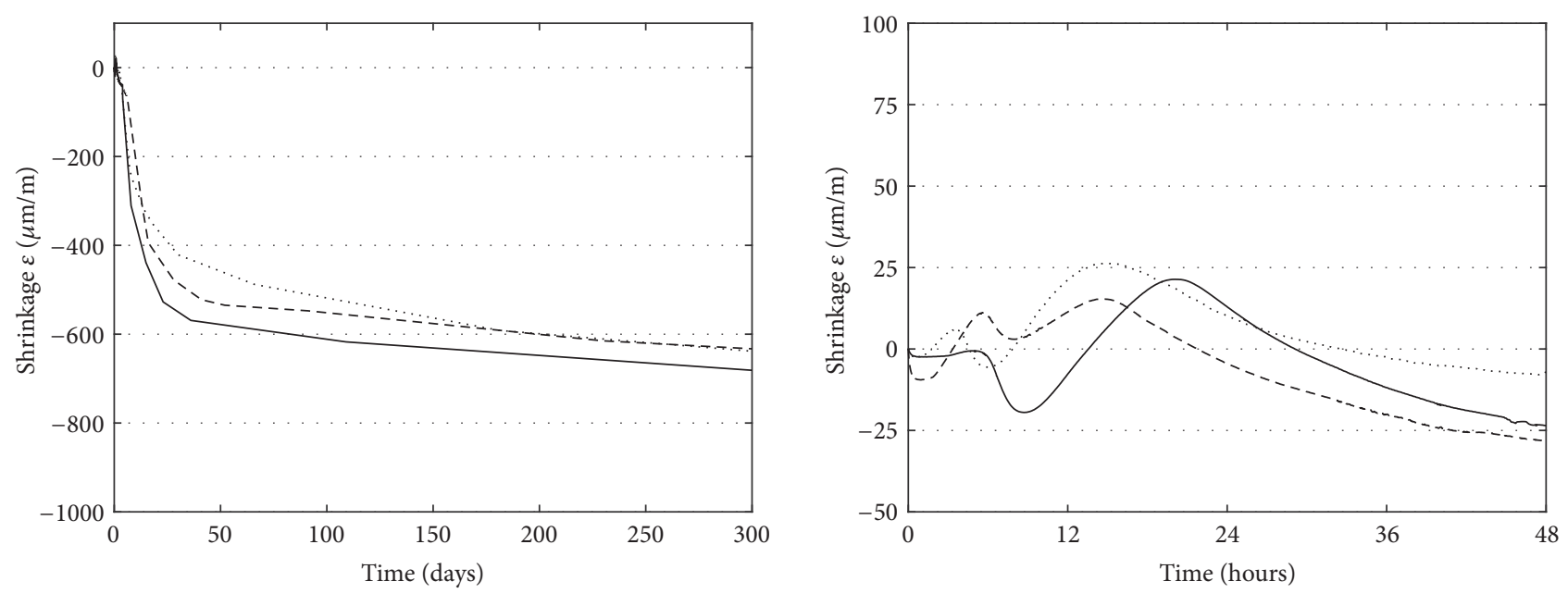

$1 / 1$

$---1 / 2$

… $1 / 3$
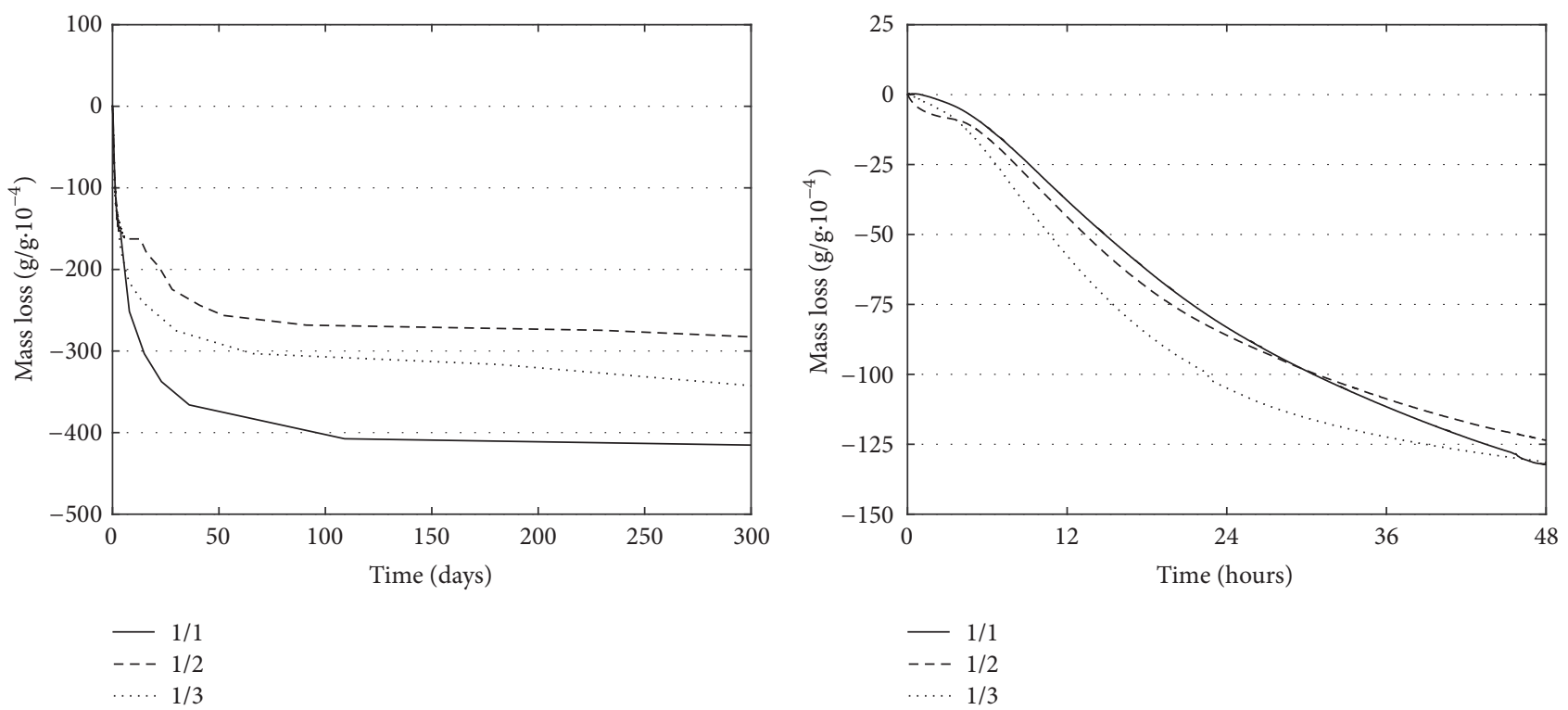

(a)

(b)

FIGURE 8: Progress of shrinkage/swelling and mass loss for concretes 1/1, 1/2, and 1/3 ((a): measurement over the whole time of setting and hardening; (b): early age measurement).

dosage, during the first 24 hours of ageing, all mixtures exhibited swelling the magnitude and progress of which were influenced by the content of cement and water. Generally speaking, the higher the cement dosage was, the greater the value of volume increment recorded was. In absolute values, Figure 4(b) on the upper part ranges approximately from 35 to $85 \mu \mathrm{m} / \mathrm{m}$. However, a simultaneous loss in mass was registered in this stage as well. Concretes with plasticiser see a reduction in the value of swelling. Also, the curves of initial volume changes recorded during the first 48 hours of measurement differ significantly in comparison with concretes without plasticiser. In terms of the absolute values of total deformation, the observed influences (cement and plasticiser content) are not very significant. The measured progress of shrinkage well corresponds with the progress of mass losses. Concerning the absolute value of shrinkage determined at 300 days of age, all the examined concretes range from 650 to $850 \mu \mathrm{m} / \mathrm{m}$. However, differences were recorded in the time at which deformation stabilised. Concretes without plasticiser saw a relatively sharp increment of shrinkage before the age of 90 days after which they began to stabilise. After the plasticiser had been added, the progress of shrinkage slowed down in approximately 30 days. In the early stage of concrete setting and hardening, the mass of concrete specimens with plasticiser, compared with the concrete without plasticiser, decreases more rapidly. It can be observed that this trend is changing approximately after 7 days of concrete ageing. Concrete swelling results usually from the action of several 


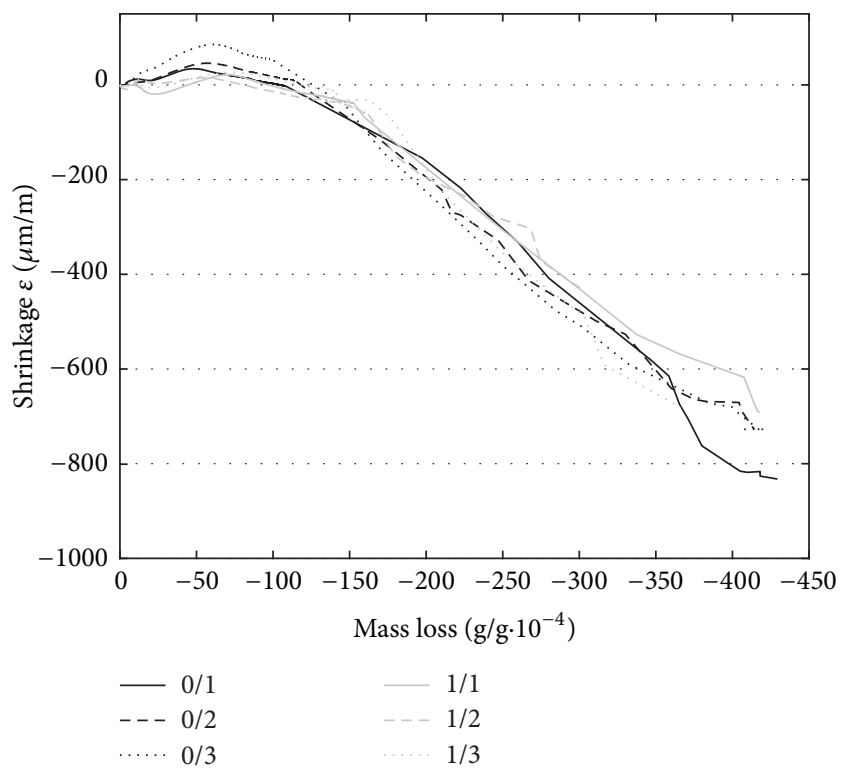

Figure 9: Relationship between shrinkage and mass loss for all investigated concretes.

factors that cause the increase in the volume of a concrete element. The most significant factors are the properties of cement, water content along with moisture distribution in the concrete pore structure, heat flow and the magnitude of hydration heat, presence of additives and admixtures, or the method of concrete curing. The particular contribution of all above-mentioned phenomena is currently the object of ongoing experimental measurements.

\section{Conflicts of Interest}

The authors declare that there are no conflicts of interest regarding the publication of this paper.

\section{Acknowledgments}

This paper has been written as part of the Project no. 1714302S "Experimental Analysis of the Early-Age Volume changes in Cement-Based Composites," supported by the GACR-Czech Science Foundation.

\section{References}

[1] E. Holt, "Contribution of mixture design to chemical and autogeneous shrinkage of concrete at early ages," Cement and Concrete Research, vol. 35, no. 3, pp. 464-472, 2005.

[2] E. Holt, "Early age autogeneous shrinkage of concrete," Tech. Rep., Technical Research Centre of Finland, Espoo, Finland, 2001.

[3] "PCA: the portland cement association," http://www.cement .org, 2017.

[4] A. M. Neville, Properties of Concrete, 5th edition, 2011.

[5] J. Newman and B. S. Choo, Advanced Concrete Technology: Concrete Properties, vol. 1, Elsevier, Amsterdam, 2003.
[6] M. Kratochvíl, M. Kadlec, I. Terzijski, and L. Zvolánek, "Autogenous shrinkage and its measurement since the moment of concrete casting," Technologie, Konstrukce, Sanace, vol. 14, no. 3, pp. 64-67, 2014, Praha: Czech Concrete Society.

[7] L. Barcelo, M. Moranville, and B. Clavaud, "Autogenous shrinkage of concrete: a balance between autogenous swelling and selfdesiccation," Cement and Concrete Research, vol. 35, no. 1, pp. 177-183, 2005.

[8] J. Newman and B. S. Choo, Advanced Concrete Technology: Processes, vol. 1, Elsevier, Amsterdam, Netherlands, 2003.

[9] A. Mazzoli, S. Monosi, and E. S. Plescia, "Evaluation of the earlyage-shrinkage of Fiber Reinforced Concrete (FRC) using image analysis methods," Construction and Building Materials, vol. 101, pp. 596-601, 2015.

[10] H. T. Le and H.-M. Ludwig, "Effect of rice husk ash and other mineral admixtures on properties of self-compacting high performance concrete," Materials \& Design, vol. 89, pp. 156-166, 2016.

[11] H. W. Reinhardt and C. U. Grosse, Advanced Testing of Cement Based Materials during Setting and Hardening, RILEM Publications, Bagneux, France, 2005.

[12] Schleibinger Testing Systems, http://www.schleibinger.com, 2017.

[13] A. M. Soliman and M. L. Nehdi, "Effect of drying conditions on autogeneous shrinkage in ultra-high performance concrete at early-age," Materials and Structures, vol. 44, no. 5, pp. 879-899, 2011.

[14] I. Norisham, P. Omenzetter, and P. Lipscombe, "Monitoring system for in-situ measurement of creep and shrinkage effects in a prestressed concrete bridge," in Proceedings of the 20th Australasian Conference on the Mechanics of Structures and Materials, pp. 767-771, Toowoomba, Australia, 2008.

[15] R. Sato, K. Maekawa, T. Tanabe, K. Sakata, H. Nakamura, and H. Mihashi, Eds., Creep, shrinkage and durability mechanics of concrete and concrete structures proceedings of the eighth International Conference on Creep, Shrinkage and Durability of Concrete and Concrete Structures, Ise-Shima, Japan, 30 September-2 October 2008, Taylor \& Francis, 2008.

[16] J. Stráský, M. Zich, and P. Novotný, "Bridges with progressivelly erected decks," in proceedings of the CIV - SPRING 2014, pp. 1922, Calgary, Canada, 2014.

[17] M. Zich, "The concept of a long-term monitoring of highway D47 bridges," Beton: Technologie, Konstrukce, Sanace, vol. 11, no. 4, 2011.

[18] R. Hofírek and M. Zich, "R35 sedlice-opatovice, construction of the flyover SO 206.2-monitoring of the stress in the load bearing structure," in Proceedings of the 22nd Concrete Days, Czech Concrete Society ČSSI, 2015.

[19] P. Havlásek, Creep and Shrinkage of Concrete Subjected to Variable Environmental Conditions [Ph.D. thesis], Faculty of Civil Engineering, Prague, Czech Republic, 2014.

[20] M. Collepardi, The New Concrete, the ČKAIT Information Centre for the Czech Chamber of Certified Engineers and Technicians Active in Concstruction (ČKAIT), Praha, 1st edition, 2009, 342 p. Betonové stavitelství.

[21] M. N. Amin, J.-S. Kim, T. T. Dat, and J.-K. Kim, "Improving test methods to measure early age autogeneous shrinkage in concrete based on air cooling," The IES Journal Part A: Civil \& Structural Engineering, vol. 3, no. 4, pp. 244-256, 2010.

[22] A. Bentur, Ed., Early Age Cracking in Cementitious Systems: Report of RILEM Technical Committee 181-EAS 'Early Age 
Shrinkage Induced Stresses and Cracking in Cementitious Systems', RILEM Publ, Bagneux, France, 2003.

[23] E. Marušić and N. Štirmer, "Autogenous shrinkage and expansion related to compressive strength and concrete composition," Journal of Advanced Concrete Technology, vol. 14, no. 9, pp. 489501, 2016.

[24] M. Matysik, L. Topolar, P. Danek, T. Vymazal, and I. Plskova, "The effect of concrete quality on the acoustic emission parameters during three-point bending fracture test," Advanced Materials Research, vol. 897, pp. 149-152, 2014.

[25] H. Šimonová, I. Havlíková, P. Daněk, D. Lehký, B. Kucharczyková, and Z. Keršner, "Effect of cement dosage on selected mechanical fracture parameters of concretes," Applied Mechanics and Materials, vol. 617, pp. 239-242, 2014.

[26] H. Šimonová, I. Havlíková, P. Daněk, Z. Keršner, and T. Vymazal, "The effect of a superplasticizer admixture on the mechanical fracture parameters of concrete," Materiali in Tehnologije, vol. 49, no. 3, pp. 417-421, 2015.

[27] L. Topolář, K. Timčaková, and P. Misák, "Influence of superplasticizer quantity on formation of micro-cracks during setting and hardening of concretes by acoustic emission method," Advanced Materials Research, vol. 1124, pp. 219-224, 2015.

[28] ČSN EN 12350, Testing of Fresh Concrete, Czech Standards Institute, Prague, Czech Republic, 2009, (this standard is the Czech version of the European Standard EN 12350), 8 P.

[29] B. Kucharczyková, P. Daněk, P. Misák, and T. Vymazal, Apparatus for Measuring Relative Deformation of Concrete And Cement Composites, Czech Republic, 2011, CZ 21600 U1 Utility model. Applied 13.10.2010. Granted 12.1.2011. Entered 3.1.2011. Available: http://www.upv.cz/en/ip-rights/patents.html.

[30] T. Vymazal, P. Daněk, B. Kucharczyková, and P. Misák, "Continuous measurement method of cement composite weight losses in early phase of setting and hardening, and apparatus for making the same," 2015, Czech Republic, CZ 304898 B6 Patent. CZ 304898 B6 Patent. Granted 26.11.2014. Entered 7.1.2015. Available: http://www.upv.cz/en/ip-rights/patents.html.

[31] B. Kucharczyková, L. Topolář, P. Daněk, D. Kocáb, and P. Misák, "Comprehensive testing techniques for the measurement of shrinkage and structural changes of fine-grained cement-based composites during ageing," Advances in Materials Science and Engineering, vol. 2017, pp. 1-10, 2017, https://www.hindawi.com/ journals/amse/2017/3832072/.

[32] ČSN 73 1372, Non Destructive Testing of Concrete-Rezonance Method for Concrete Testing, ÚNMZ (in Czech), Prague, Czech Republic, 2012.

[33] P. Rovnaníková and O. Žalud, Effect of Admixtures and Fine Grain of Aggregate on the Portland Cement Hydration, Faculty of Civil Engineering, Brno, 2015, (Czech). 

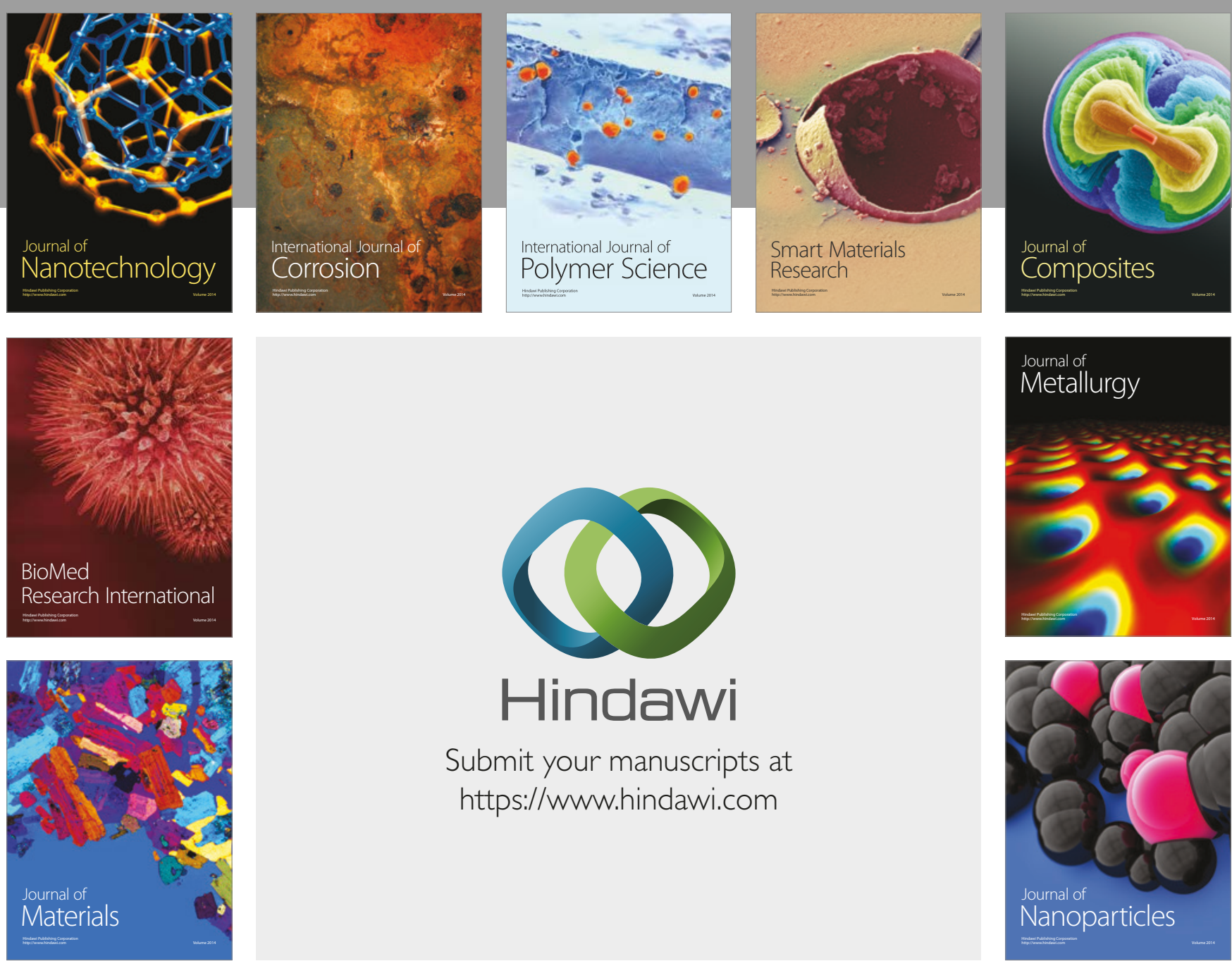

\section{Hindawi}

Submit your manuscripts at

https://www.hindawi.com
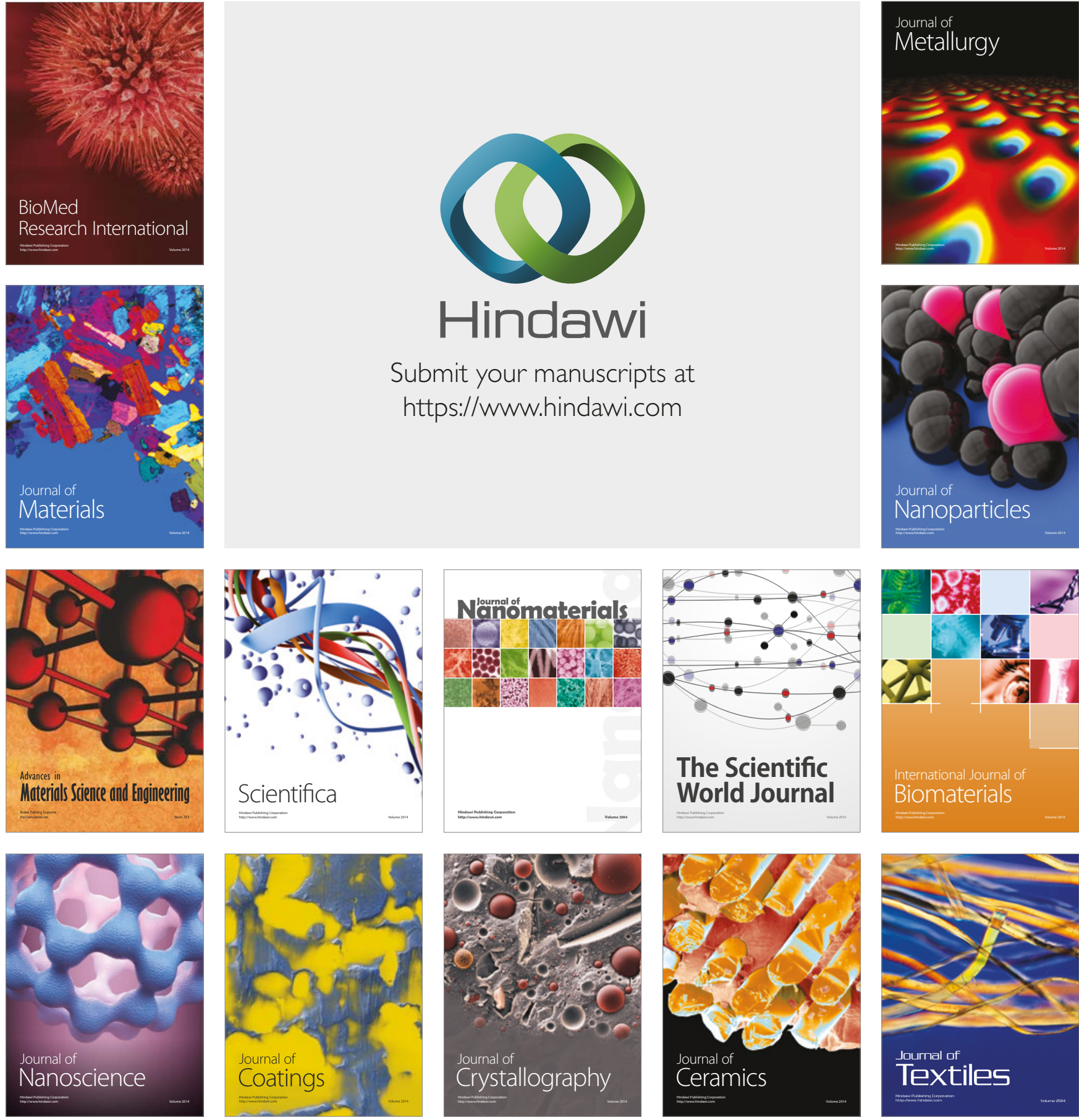

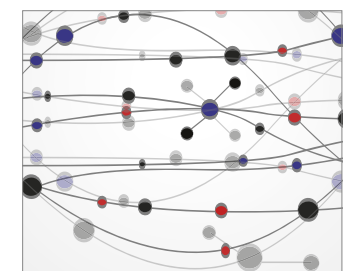

The Scientific World Journal
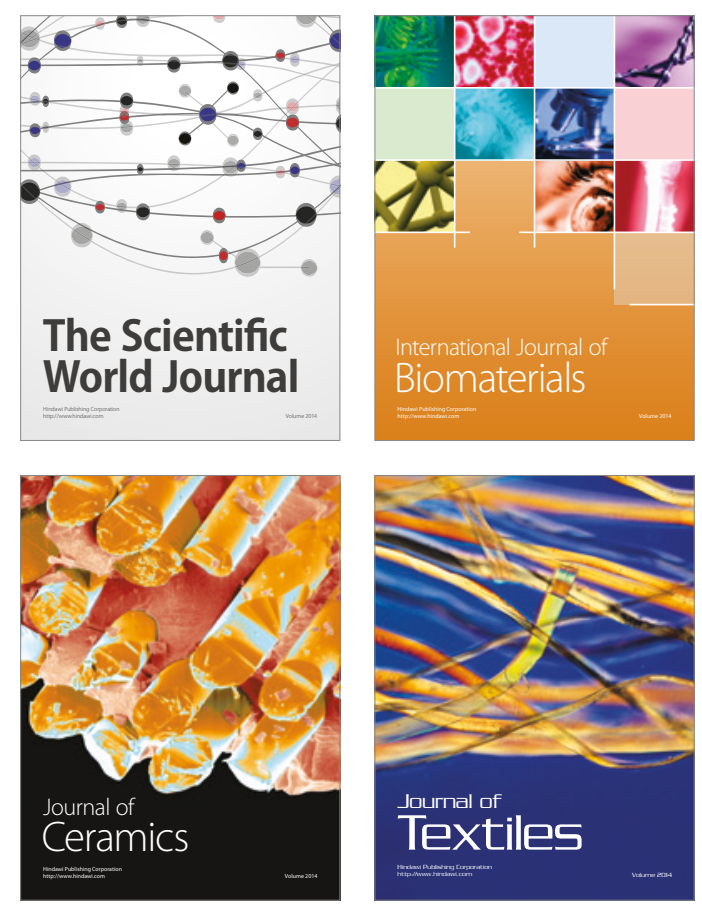